\title{
Unity, simplicity and balance: sustainable management of cultural historic environments of mountain summer farming
}

\author{
G. Swensen \\ The Norwegian Institute for Cultural Heritage Research
}

\begin{abstract}
Ecologically based architecture aims to maintain a long-term harmony between the built environment and nature. It assumes that there is a close, interlocked connection between natural conditions and cultural expressions, a unitary and holistic comprehension of time and space, and a belief in one's ability to influence the long-term effects of technological development in an ecologically beneficial way. In this paper these hypotheses will be viewed in light of some basic principles on which the structures of traditional building forms have been based. Special emphasis will be put on the relationship that has long existed between the built environment and the landscape. This approach will be illustrated by the presentation of a traditional regional type of dwelling still found in active use in some mountain areas in Norway and by the ways farmers adapt to the demands set by modern farming directives. The paper is linked to an ongoing interdisciplinary research project: "Redefining Rural Resources - Local capacity-building in sustainable management of cultural historic environments of mountain summer farming".

Keywords: cultural historic environments, cultural heritage protection, sustainability, ecological architecture, vernacular architecture, mountain summer farming.
\end{abstract}

\section{Introduction}

\subsection{Main perspectives}

This article should be seen as a small contribution to the basic discussion on which cultural heritage management is based, namely how to secure a viable role 
for enduring cultural historic environments in meeting the challenges set by modern forms of production. It is illustrated by a region where mountain summer farming still plays a vital role and the article primarily focuses on one aspect of mountain summer farming, namely the dwellings and the cultural historic environment and landscape of which they form an integral part.

The mountain summer farm constitutes a cultural environment of material components: buildings and other built structures (fences etc), surrounding areas (pasture, mowing land), as well as immaterial connections. Today the owners find themselves in the intersection between several trends: agricultural readjustments leading to either a reduction in or the discontinuance of mountain summer farming - a developing tourism industry based on an appreciation of national heritage - and expanding areas of modern holiday homes and outdoor pursuit centres in key mountain regions. Are the characteristics of the built environments that are recognised as assets for local farmers commensurate with the technical demands, agricultural regulations, and economic framework to which today's farmers have to adapt? The primary question in this context is: can the basic principles of forms, constructions and plans on which traditional types of dwelling are based be sustained and developed from an eco-architectural perspective to meet the demands today's mountain farmers face, thus managing to maintain the tight-knit bond between landscape and forms of settlement?

This paper is linked to an ongoing interdisciplinary research project: "Redefining Rural Resources - Local capacity-building in sustainable management of cultural historic environments of mountain summer farming" $(2005$ - 2007). Two case studies will be carried out in different regions with active summer mountain farming. The analysis will entail study at three different levels: 1. A critical review of relevant official documents and proposed and approved plans 2. Qualitative interviews with key actors participating in the local capacity-building process 3 . A field study, including systematic observations in the selected localities. This article presents some reflections based on the first case study, with references to some of the key official documents as well as to information from some of the 13 interviews.

\subsection{Presentation of some key concepts}

Discussions about sustainability reflect a growing concern for the environment. Place-based communities have become central to a holistic concept of sustainability which integrates environmental, economic, political, cultural and social considerations. It rests on a recognition that the safeguarding and preservation of nature and cultural environments must be grounded in the communities and societies which utilise and depend on them (Richards and Hall [9]). This strong emphasis on the local community constitutes the premise on which this article will be based.

When sustainability is referred to in discussions about ecological architecture, aspects such as technology, renewability and traditional wisdom are focused on (Butters and Østmo [2], Williamson [16], Phillips [7], Thompson [14]). According to James Steel, the need for sustainable development has led to a new way of looking at materials and form, opening the way to a greater willingness to 
replace scarce resources with renewable materials. This requires looking beyond fashion to a more durable approach to design. A more open minded attitude has moved the perspective towards learning from traditional building methods and realising "that local architecture grew out of many trial and error attempts to deal with natural phenomena and should be respected as a repository of wisdom" (Steel [11]). The sustainable management of cultural historic environments characterised by active contemporary use gives rise to examples where such knowledge is needed by the participants involved at all levels - farmers, builders, and management officials. The challenges being set by modern operating methods require the redefinition of cultural historic resources in a new setting, though on the terms stipulated by the old buildings and the context of their environments.

\section{Case study: Budalen - a region dominated by active mountain summer farming}

\subsection{A local example}

Budalen was selected as case study due to the active summer farming which has taken place here for generations. According to the list of farmers receiving production subsidies in the municipality, 28 farmers were practising mountain summer farming here in 2004. Of this total, 17 of the mountain summer farms are situated within a landscape protection area (Endal and Budal). In this part of the municipality the number of active mountain summer farmers has stabilised during the last ten years.

Traces of mountain summer farming in this region can be found from as far back as the middle of the $17^{\text {th }}$ century, and during the subsequent 200 years a series of summer farms were established. The main reason for the continuous summer farming is the need for supplementary animal fodder. The main farms are situated in a region where the summers are too short to provide enough cultivated grazing land for the livestock. During the peak summer months, normally between 1 st July and 1st September, the livestock is moved into the valleys to supplementary grazing land in the mountainous area.

The two valleys are reminiscent of two arms stretching out towards a remarkable mountain formation named Forollhogna. Endalen is situated in the western part of the region. It is a relatively open valley situated approximately $700-1,100 \mathrm{~m}$ above sea level and stretches over approximately $35 \mathrm{~km}$. Today the valley has no milk round, which means that the dairy products have to be produced at the summer farms. There are three active milk farmers in Endalen, with the rest of the dwellings being run by sheep farmers. All the land in this valley is owned by the state. The eastern valley, Budalen, which has given its name to the whole region is slightly shorter than its neighbouring valley. A few of the summer farms are privately owned in its southern part. The daily milk round forms the economic basis on which today's summer farming is based, though the so-called niche production of traditional milk products plays an important supplementary role. 
As a mountain region, Forollhogna is a popular habitat for large herds of wild reindeer and other rare wildlife. Because of this the region was turned into a protected national park in 2001. The two neighbouring valleys where the summer mountain dwellings are situated are listed as landscape protection areas, which means they are subject to restrictions concerning building alterations, rebuilding, etc. The main focus is still on the maintenance of active farming, which to a large degree influences how the regulations are interpreted and applied.

\subsection{Mountain summer farming - a cornerstone of Norwegian agriculture}

From a situation 150 years ago where almost every farm had a summer mountain farm, and some farms even had more than one, about 1,200 summer mountain farms are currently in use (Norsk seterkultur 2003).

The fact that a lot of farmers found it financially unsatisfactory to maintain mountain summer farming led to a dramatic reduction after 1945 due to major changes within the rural sector. Sør-Trøndelag, the county in which Budalen is located, had more than 2,000 active mountain summer farms in 1939. By 1998, the total number had fallen to 425 . The threat this trend represents with respect to losing key assets has caused both the rural and the cultural heritage sector to act. Different forms of grants have therefore been introduced, both for community development and cultural landscape management. This has resulted in a slight increase in summer farming since the lowest level was reached in 1989, and between 1989 and 1998, 71 farmers decided to start up again in Sør-Trøndelag (Statens Landbruksbank [10]).

The summer farming in Budalen typifies a Norwegian mountain summer farming region in the sense that it blends into a pattern of multifunctional agriculture that represents an adaptation to the particular climatic conditions farmers in this country have always had to face. At the same time its character makes it unique: partly because of the close-knit unity which still exists between the landscape and dwellings, and partly because of the strict regulations to which the summer farm region is subject as part of the landscape protection. The level of degradation has reached a higher tempo in most other regions.

\section{Traditional buildings as part of today's landscape}

\subsection{Some basic principles of traditional wood building techniques}

The importance of upholding certain general rules that govern the traditional use of wood as a building material was stressed in a recently completed project, which has led to a greater focus on how traditional techniques can be transferred to a modern setting. Particular attention is paid to principles such as:

- The principle of adequacy, which states that the optimal quality of the raw material is that which is good enough for the job. While certain exposed parts of a building require top quality timber, others are adequately cared for by using poorer materials. 
- The complementary principle of protective construction, which pervades much of our architectural heritage and is embodied in numerous methods aimed at ensuring buildings maximum lifetimes (methods and constructive elements to ensure ventilation, combat rot, preventing the entry of water, etc.) (Egenberg 2004b:6)

\subsection{A short description of the regional building traditions}

The mountain summer farms in the two valleys are located according to the topography. Unlike the main farm settlement, no distinctive farmyard structure dominates. There is however a slight tendency to place the buildings in a row, in which case the mountainous landscape formation often plays an important role. The Swedish architectural historian Finn Werne [15] has introduced group form as a concept in his studies of traditional peasant buildings. It describes an open and dynamic form in which new parts or elements can be added and others removed or changed without the unity or pattern being broken. Group form is characteristic of the building traditions in the old peasant society. It grew out of several social and particular phenomena, and is related to a complex network of routines, customs, traditions, knowledge, motivations, roles and material preconditions. It is typical of ordinary building constructions and is significantly distinct from architecture as a formalised art form.

A mountain summer farm in this area normally consisted of three main building types: a house built as a combined dwelling and storehouse ("seterbu"), a cow barn, and a hay barn. In addition to this, separate cookhouses and storehouses were common on most mountain summer farms. Smaller hay barns were also situated outside the building cluster nearer to the hay outfields. The combined dwellings and storehouses were quite small, between $4-5 \mathrm{~m}$ long. They normally had three rooms. The entrance led into a combined hall and storehouse ("skjæle") and from here into the room with the fireplace, a room combining several functions: cooking, sleeping and recreation ("bu"). On the other side was a cool storehouse ("masbu") without windows for storing dairy products. The outbuildings were generally laid out as one-storey buildings with one room. There are also examples of combined outbuildings, for instance cow barns extended with hay barns. A few cow barns had a cellar for manure, but more commonly there was an opening in the gable wall. Most buildings had natural stone foundations or rested on cornerstones. The construction method most frequently used was cogged joints, often in combination with a timber framework. To keep the roof waterproof a layer of birch bark was placed between the roof boards and a layer of turf. These old techniques fell out of use when galvanized sheets were introduced. The buildings were designed to be utilitarian and ornamental details were only sparsely incorporated (SørTrøndelag County Council [12]:6-9).

\subsection{Restrictions set by the landscape protection regulations}

Since many of the areas are owned by the state, a special set of rather strict regulations apply ("Seterforskriftene"). However, there is a willingness to open 
the way for new activities aimed at producing supplementary income such as tourism and culture based services. There is an assumption that such combinations are necessary to maintain mountain summer farming.

The active milk farmers today use generators to run their milking machines, and solar panels for general lighting. Permission has been granted for the provision of electricity to the valley in the future. Buried cables have been recommended, but financial considerations are currently preventing installation (Forvaltningsplan [6]: 17, 18). When it comes to the buildings, the importance of protecting the landscape against interference (for instance erecting new buildings, demolishing old farm buildings) is highlighted as the primary function. Room has however been made for exceptions and such applications are generally accepted when their purpose is to erect buildings that are necessary to enable summer farming and grazing, or to allow either restoration or rebuilding for farming purposes. It is also possible to apply for permission for a change of use. Except in the case of ordinary maintenance, all applications concerning the dwellings are considered by cultural heritage officers at a county level (Forvaltningsplan [6]: 19-21).

\subsection{Conflicting interests between conservation and modern farming?}

In a handbook published by the county's cultural heritage department, the farmers are asked to take account of old building traditions when it comes to reparation, maintenance and new buildings. When it comes to new buildings, the importance of orienting them according to the longitudinal direction of the valley is stressed. In addition to this, extensions also have to be built lengthwise and not at an angle. Do such approaches represent a basis for conflicts?

There are two main reasons why a need to alter a building arises. One is the need to add an extension to the combined dwelling and storeroom in cases where a farmer is hoping to rent out rooms to tourists. So far only one or two such cases have been handled by the municipality's Building Inspection Department.

The other major group of buildings undergoing reparation, alterations or rebuilding are the cow barns. Any buildings in which milk products are processed for retail are today classified as production buildings and have to meet the specifications set by the agricultural authorities. The requirement to conserve the old cow barns while complying with new demands has led to interesting experiments. The so-called "milking stable" complies with the detailed specifications concerning dimensions linked to the size of the herd. Old cow barns would neither be high nor bright enough to satisfy today's standard. The milking stable is used as a temporary shelter while the milking takes place. The livestock is let out again as soon as the milking is over, and the time consuming job of removing manure no longer exists. Not all of the mountain summer farmers have found the milking stable experiment satisfactory. One argument against it is animal welfare, since cold mountain nights can be harsh. According to anecdotal stories, cows belonging to farmers with a milking stable tend to mix in with other herds in an attempt to get shelter. The new cow barns which are being erected to house a normal herd of between $12-16$ cows need to be bigger than the old cow barns to satisfy current directives. A few such barns are 
extensions of old buildings with stipulated height requirements being met by digging down and constructing new foundations. However, most of the new cow barns differ from the old in construction, length, dimensions and materials.

A local builder specialises in erecting buildings with cogged joints. He is himself a mountain summer farmer. When he needed to restore some of the buildings on his own summer farm, he took courses so he could restore his own buildings. Today he is running a small building business and has delivered two buildings to mountain summer farmers in the two local valleys. There seems to be local demand for this sort of specialised knowledge, but no apparatus for channelling the demand in the right direction.

Plans for using old buildings in new ways are normally approved by the municipality's Building Inspection Department. At the moment there are new plans to restore cookhouses. Another idea planned for some time in the future concerns restoring a collapsed barn and turning it into guest accommodation.

The financial backing which makes such plans possible is sought from several sources. An annual subsidy is distributed at the county level to all mountain summer farmers and there also are several other grants. You need a wellestablished network and good advisors in order to be familiar with these possibilities. The rural advisor employed by the municipality plays an important role here and is referred to by most of the interviewees. Being a part-time mountain summer farmer himself, he has an insight into the nature of the job, which is now largely aimed at combining active use and protection.

Many other challenges faced by farmers on a daily basis stem from regulations concerning hygiene and health directives for agricultural food production. Those farmers who are interested in placing more emphasis than before on specialised milk and cheese production, have to comply with directives which are unsuitable for these goals. As one of the farmers put it: "We have to follow the same procedures in these mountain areas as a chef in a gourmet kitchen in the capital".

\section{A discussion of mountain summer farms in relation to eco-architectural principles}

\subsection{Influence and local participation}

The legislation that ensures the protection of valuable areas contains an inbuilt potential for conflict, regardless of whether one is talking about natural resources or cultural heritage assets. The formal decisions are primarily made at a state or county level, which creates a need for constructive dialogue to enable local opinions and suggestions to be taken into account. Without an understanding of local factors much of the effort to ensure protection is likely to fail. Not surprisingly the initial discussions about protection where met with a lot of scepticism in Budalen. The farmers were afraid that strict regulations would impede active summer farming which had survived during a long period of continuous adjustments. During a period dominated by discussions the scepticism has slowly worn off. Now the dominant viewpoint seems to be an 
understanding of the potential being generated. This is due to the engagement of several parties, not least initiatives at the municipal and county level. Active farmers are involved in courses and inspire each other to try new methods in accordance with handed-down knowledge. Due to a greater awareness on a national level of the cultural landscape resources at stake, recent changes to the government's rural policies have made it easier to direct grants and subsidies towards active mountain summer farming areas. Thus new initiatives have been created which have resulted in a new optimism among the farmers.

\subsection{Ensuring harmony between built settlements and the surrounding landscape}

The interviewees have surprisingly uniform opinions when asked what the main assets of the valleys are. The primary value they mention is the harmony that exists between the landscape and the settlement, which make it unnecessary and impossible - to rank one particular settlement above the others. The explanation given for this is the continuous and vital role it plays in ensuring their daily income. Seldom is a consensus concerning cultural values so easily reached. In this case it can be understood in light of people's shared perspective due to active practice in today's landscape. It is based on an understanding of the dialogue and dialects which exist between nature and culture. In this case the use of the Nature Conservation Act can be seen as one of the available means of ensuring the continuation of the long established harmony between the built environment and nature. By specifying the importance of continuous active use in relation to modern rural demands, the regulatory documents reveal an underlying shared understanding of the importance of maintaining the unity of time and space to which the dwellings situated in the landscape bear witness.

\subsection{The need for a new perception of the past}

Today, there is renewed interest in reviving elements from the past in most western countries. Some of this interest is based on expectations that tourism will create new economic opportunities in rural areas struggling with migration. Other reasons may have a political and ideological origin at a time when European countries are becoming more tightly woven into the fabric of the EU. In Budalen however, it is not a question of reviving, but of maintaining a way of living which has proven to be highly adaptable. During the last few years the population level has been stable. Most of the people living there regard themselves mainly as farmers by profession, even though the family economy is often supplemented by other incomes, and they want to continue as farmers for as long as an opportunity to do so exists. Getting young people interested in spending a summer season in charge of the mountain summer farm is not a problem, one of the youngest is a 17 year old girl. However, farmers in Budalen are well aware of the renewed interest in rural traditions in the tourism market and have an open mind towards new ways of combining farming, tourism and cultural tourism. The uniqueness of these valleys lies in the interplay which takes 
place here between traditional buildings and a landscape which, though dominated by biodiversity, is still in active use.

\subsection{Promoting ecological friendly building forms and methods ("green structures")}

Knowledge of the old ways of building is no longer shared knowledge because the long process of specialisation has given rise to a wide gulf between the location of production and the local market. Local craftsmen are often used in Budalen when it comes to erecting new buildings and rebuilding. But, when it comes to deciding which building materials, oils and paints to use, financial considerations count more than ecological ones. Protected areas represent an ideal basis from which to promote ecologically based solutions ("green structures") and test the potential of influencing the long time effects of technological progress in an ecologically accommodating way. These decisions however have to be made on a different level than the local market in which tight financial margins leave no room for risky experiments. A national strategic programme for testing out ecologically based solutions in protected mountain summer farming areas would be an interesting test case to promote.

\section{Concluding remarks}

The main focus of this article has been how the conservation of cultural historic environments can be combined with the practical contemporary use of the buildings in a satisfactory way from a social, financial and ecological point of view. By choosing the situation which occurs in the somewhat "ideal" setting of a landscape protection area as an example, the article illustrates some of the milder practical problems which occur when farmers try to combine an historical interest with the obligations today's farming directives set. The interconnectedness which exists between landscape and settlement in the example region of mountain summer farming has been underlined as the major quality by all the parties involved in activities in this area.

Those actively participating in the development of modern "taskscapes" (Ingold [5]) can find a lot of inspiration from traditional ways of building. A continuous and constructive dialogue concerning the adaptation of new building types and styles in conservation areas should be a requirement, and we should encourage proponents of ecological architecture to participate in this discussion. There is a need for more pioneers to develop solutions that can work within the new financial, social and ecological limits today's farmers encounter. The "repository of traditional wisdom" inherent in cultural historic environments can be seen as a rich source of inspiring new solutions.

\section{References}

[1] Bladh, Gabriel 1995: Finnskogens landskap och människor under fyra sekler - en studie av natur och samhälle i forändring. Göteborg University. 
[2] Butters, C \& F.Østmo 2001.Bygg for en ny tid. Mot en miljøvennlig arkitektur - 127 norske eksempler. Oslo: Norsk arkitekturforlag.

[3] Egenberg, Inger Marie 2004a. Tre i tiden. Tradisjonsbaserte løsninger. Oslo: The Norwegian Institute for Cultural Heritage Research.

[4] Egenberg, Inger Marie 2004b. Timber for Today. In: NIKU Annual Report 2004. Oslo. Available at http://www.niku.no

[5] Ingold, Tim 2000. The Perception of the Environment. Essays in livelihood, dwelling and skill. London/New York: Routledge

[6] Municipality of Midtre Gauldal 2005. Forvaltningsplan for Endalen, Budalen, Forddalen. Landskapsvernområder.

[7] Phillips, Christine 2003. Sustainable place. A place of sustainable development. Chichester: Wiley-Academy.

[8] Norsk seterkultur 2003: Seterbrukaren. Skrift frå Norsk seterkultur, nr.34/2003.

[9] Richards, Greg \& Derek Hall (eds.) 2000: Tourism and Sustainable Community Development. London / New York: Routledge.

[10] Statens Landbruksbank 1999. Prosjekt seterbruk i Norge. Status og virkemidler. Rapport for fase 1.

[11] Steel, James 2005. Ecological Architecture. London: Thames \& Hudson Ltd.

[12] Sør-Trøndelag County Council, Department of Culture 1994: Verneplanarbeide Gauldalsvidda Forollhognaområdet. Trondheim.

[13] Sør-Trøndelag County Council, Department of Culture 2002: Nybygging i seterlandskapet. En mini-håndbok for eiere av setrer i Sør-Trøndelag.

[14] Thompson, Ian H. 2000: Ecology, Community and Delight. Sources of values in landscape architecture. London/New York: Spon press:

[15] Werne, Finn 1993. Böndernas bygge: traditionellt byggnadsskick på landsbygden i Sverige. Stockholm

[16] Williamson, Terry, Antony Radford \& Helen Bennetts 2003. Understanding sustainable architecture. London/New York: Spon Press. 